
\title{
BResarch Soute \\ Exploring the patterns of a multisectoral approach in fighting COVID-19 pandemic in SNNPR, Ethiopia: A qualitative case study approach.
}

Abraham Ali ( $\square$ alanoabraham@yahoo.com )

Policy Study and Research Institute, SNNPR

Akmel Usman

Policy Study and Research Institute, SNNPR

Fekadeselassie Badebo

Policy Study and Research Institute, SNNPR

Solomon Tilahun

Policy Study and Research Institute, SNNPR

\section{Research Article}

Keywords: COVID-19, Multisectoral approach, collaboration, coordination case study

Posted Date: December 4th, 2020

DOI: https://doi.org/10.21203/rs.3.rs-110493/v1

License: (c) (i) This work is licensed under a Creative Commons Attribution 4.0 International License.

Read Full License

Version of Record: A version of this preprint was published at PLOS ONE on February 25th, 2022. See the published version at https://doi.org/10.1371/journal.pone.0263667. 


\section{Abstract}

Background Since COVID-19 has been declared as a global pandemic, South Nations, Nationalities People's Region has been doing its level efforts by establishing high level task force across the region. The disease is a new one with multifaceted challenges requiring consolidated efforts, there is inadequate understanding about the patterns of the efforts and collaborations of various stakeholders in the region. Therefore, this study has explored the patterns of the multisectoral collaboration in the fight against the COVID-19 in the region using a qualitative case study design. Data were collected by key informant interview and document review and analyzed using a content analysis framework focused on case study data analysis.

Result The study has indicated a unique perspective in establishing functional multisectoral approach with strong courage and motivation of most involved stakeholder. Almost all stakeholders have shown clear understanding about the multidimensional burdens the disease could cause and the necessities for joint efforts to tackle the multidimensional problems. The study further elucidated that despite the encouraging beginning, the eventual slowdown undertakings in the joint actions. This included failure to meet regularly to monitor and evaluate as stated earlier and societies' reluctances despite continues information dissemination.

Conclusion Based on the study findings it can be concluded that the disease has created significant worries up on the society and stakeholders, thus, called for strong multisectoral actions. The occurrence of this disease has not only come up with numerous challenges but also with significant opportunities that can be strengthening in the future. Hence forth, the study recommends strengthening the established multisectoral approaches and timely correction of the observed drawbacks.

\section{Introduction}

Multisectoral collaboration is an approach that involves various expertise and capacities to solve multiple dimensions problems which are beyond the competence of single sector or institution [1, 2]. Multisectoral approach (MSA) refers to "deliberate collaboration among various stakeholder groups (e.g., government, civil society, and private sector) and sectors (e.g., health, education, environment and economy), jointly achieve a policy outcome" $[3,4]$.

Different challenges that had been encountered necessitated the collaborative efforts of various stakeholders in the history of mankind and, health related matters can be cited forefront among others [57]. In relation to this, the establishment of World Health Organization (WHO) represents the demand for collective efforts in improving global health outcomes $[8,9]$.

The outbreak of COVID-19 is one of the world's grave pandemic that crossed national boarders within a very short period of time $[10,11]$. Moreover, it has been the causes for the infection of more than thirty two million people around the world and has been reason for the death of close to million lives until 
September 24,2020 . The WHO, as the global leading organization is responsible for health affairs, and called for all concerned entities to put their efforts together.

As experiences show nations which have consolidated efforts reduced the impacts of the disease and shortened its time span. For example, China, aggressively intervened and could limit the progression of the disease and controlled it within short period of time [12]

The government of Ethiopia responded to COVID-19 pandemic by defining the issues as national priority and immediately established a ministerial committee which is chaired by the prime minister of the federal government. Similarly, several sub ministerial committees were established to support efforts of crisis management. Moreover, the Ethiopian parliament declared a state of emergency in an effort to fight the disease and, several rules, protocols and regulations are established are currently in action $[13,14]$.

The Ministry of Health of the Federal government of Ethiopia $(\mathrm{FMOH})$ carried out necessary preparations to tackle COVID-19 pandemic including the allocation of resources, development of a uniform preventive and treatment protocols to guide the implementation at health care system throughout the country under central command which is believed to be a good decision to tackle the problem. As the result, inter alia, a national comprehensive COVID-19 management document was developed and distributed to all concerned stakeholders, primarily the $\mathrm{MOH}$, Regional and City Administrations to guide the implementation [15].

Regional governments and city administrations engaged in fighting the disease in collaboration with the federal government. Moreover, civic organizations, multi-lateral and bilateral organizations, NGOs and GOs, universities and research institutions, religious institutions and the public at large deeply involved in the fighting of the disease and by the succinct technical guidance of the minister of health, all stakeholders involved in running the prevention and control of COVID-19.

Similarly the SNNPR government has established regional taskforces in the response to COVID-19 pandemic and meticulously engaged to tackle it.. On the other hand, the nature of the disease is not yet well studied and remains unclear, and no one can precisely predict the end of the crises and will become under control. Therefore, the efforts undertaken shall be geared towards the magnitude and complexity of the problem. Hence, it is important to document and present the patterns of multisectoral approach to tackle the problem comprehensively and stretched manner in region. The study was conducted to explor the patterns of collaborative efforts of the multiple actors who engaged in prevention and control of the COVID-19 pandemic.

The significance of the study is to learn lessons the process of implementation and fill the gaps observed in the undertaking. At the same time, the findings of the study would help to improve the energy of the actors by providing proper recommendations and the experience will be a spring boards for similar actions the future.

\section{Materials And Methods}




\subsection{Study area}

The study was conducted in South Nations, Nationalities and People's Region (SNNPR) before the declaration of the Sidama as an independent state. The region is one of the nine regional administrations and two city administrations make up the federal republic government of Ethiopia [16]. The capital of the region, Hawassa, is located $275 \mathrm{KM}$ south of Addis Ababa, on the main high way to Moyale -Kenya. SNNPR is administratively divided into 18 zones, one city administration and seven special woredas[1]. The region is well known for its ethnic, cultural, linguistic and geographical diversities. It is thus, hosts for 56 ethnic diversities which is more than the three-fourth of the national diversities. Based on the population projection of 2007 , the regional population is estimated to be 22 million $[17,18]$. The region is one of the densely populated regions of the country.

In terms of health facilities and health services delivery the region is has covered 90 percent regarding the primary health services (health posts). There are 79 hospitals, 729 health centers and 3961 health posts. and 769 private pharmacies and drug shops and 2 diagnostic centers in the region.

Regarding the preparedness of the regional government to prevent and control COVID-19 pandemic, the region established and prepared 19 treatment centers, 02 test centers, 34 quarantine, 57 isolation centers. The region further organized 6 surveillance teams in different parts and, there are four RRT and 2 laboratories having 30 staff members [19].

\subsection{Conceptual framework}

The study was guided by the convergence model for the exploration of the patterns of the multisectoral approach. The 'Convergence' Model: Convergence can be characterized as the extent to which sectors, stakeholders, and administrative levels have been organized to work together with respect to a response across sectors for a certain issue. Convergence for responses across sectors can be understood along a continuum, from cooperation (least convergence with sectors all working on a single issue, but maintaining separate remits, activities, and plans) to integration (full convergence with sectors sharing structures, resources, and merged remits) [20].

Prevention and control of COVID-19 demand multifaceted efforts. Some of the actions are sector specific and others are cross-cutting. Therefore, the convergence model with varying level but closely managed multisectoral model is chosen.

\subsection{Study Design}

This study has employed a case study approach of the qualitative design. Case study is an in-depth empirical method, using multiple sources of evidence, that attempts to systematically investigate unfolding and development of a complex events within its context $[23,24]$. 


\subsubsection{Sampling and sampling frame}

A purposive sampling technique was employed for this study with the potential of offering maximum flexibility to enroll the key informants with rich information [25]. Bureaus, departments and offices at respective hierarchy with heightened probability of the disease impact and closely works with the health sectors were included in the study. Other organizations/ institutions such as non-governmental organizations and civic organizations were enrolled purposively in accordance to their level of involvement and previous acquaintances with the regional health bureau in one way or another.

President's office/ chief administrator office, Bureaus of Health, Agriculture and Natural Resource Development, Water Energy and Irrigation Development, Women, Children and Youth Affairs, Urban and Housing Development, Transport and Road Development, Finance, Education, Labor and Social Affairs, Government Communication, Debub TV and Radio, Coalition of Religious institution, Civic Organization (Teacher's Association) and The Ethiopian Red Cross Society, Debub Branch were involved in the study.

One third of the zones with larger population sizes and related high risk for the covid-19 exposure were enrolled for the data collection. Accordingly: Sidama, Gurage, Wolaita, Gedeo, Gamo and Hawassa City Administration were chosen.

At the zonal level also those departments with close concern and undertakings to COVID-19 prevention and control were included. These were: Office of the Administrator, Departments of Health, Education, Agriculture, Water, Sanitation and Energy, Women, Children and Youth Affairs, Labor and Social Affairs, Finance, Urban and Housing Development and Transportation and Road Development.

\subsubsection{Data collection}

The study has employed key informant interview and document review to collect information. Key informants enrolled based on their position in the organization and acquaintance to the overall institutional affairs and their level of involvement to the COVID-19 prevention and control. It was due to the requirement of the copious information for a given phenomenon [26].

Data collection instrument in the form of study guide question was developed against the study objectives by consulting literature and adopting from similar source including all necessary actions have been taken by collaborating partners. The study guide has encompassed all important dimensions related to the planning, intervention, monitoring and evaluation of the actions. The instrument was commented by professional team for its adequacy and completeness. Data collectors were recruited based on the professional background and previous qualitative data collection experiences. Accordingly, professionals at least with a first degree were involved. Orientation was provided for a day on how to competently collect data (note taking during the discussion). Almost all key informants from the selected institutions were participated in the interview. The participation depended on the level of saturation of information and the capability to capture thick information. Principal investigators have moderated the interview and the assistants took note and recorded the audio tape. 
The most senior person in the organization was the preferred one for the interview; however, in the case of the absence of such a person, an immediate delegate based on the recommendation of the head of the institution was interviewed. It was done by the prior arrangement, once, the right person was designated, and communicated. The date and time for the interview was scheduled by discussing with the informant based on the convenience. On the interview day, the team was arrived 15 minutes before the interview time.

Necessary preparation was made to capture desired information. Just on time, courtesy greeting was offered and permission was requested to get in to the office. Once we got the welcoming confirmation into offer, we took chairs in the most convenient position. All instrument and audio materials were checked for the functionality before the commencement of the interview. The purpose of the study was briefly informed to the key informant and a letter of permission was given. Adequate time was given to read the support letter to the key informant and the team waited until he/she will formally allow conducting the interview. The interview was conducted by using an interview guide by giving adequate time to respond. Key informants prompted and proved to further elaborate the deep and thick information. The interview lasted for 40-60 minutes on average. All the key informants' interview sessions were conducted with the maximum care by maintaining the necessary COVID-19 prevention and control protocols.

When the interview ends, the team left the room by appreciating the informant for the time and information offered. And, notice was given when need arise, follow-up communication via phone would continue.

Secondary data were collected from document reviews. Policy related document, minutes of the meeting, decision based documents at various levels were consulted based on the checklist prepared for this purpose. Hard and soft copies of the document were gathered.

\subsubsection{Data analysis}

Data were analyzed using a content analysis of the qualitative data analysis method. The key informant interview audio taped material was transcribed verbatim in Amharic (the regional working language) and translated to English. Simultaneously, the hand written documents were organized into mature notes. Comparison and matching of the hand written summary note with the transcribed information was done. Ones all the hand written document and audio taped transcripts organized, descriptive coding was done. Following the coding, data, reduction by side noticing was done. After side noting, creating or identifying major themes, were taken place. The process has taken several consultations to the verbatim transcription and handwritten notes. Codes developed into themes and rearranging the several themes and intermarrying similar themes was done. Finally, interpretation of the themes, in line with the study objectives was conducted [27, 28]. Data from the document review were categorized according to the checklist; the availability of the desired documents, to what the implementing entities has organized and utilizes them. Findings were presented based on the major themes in line with the study objectives. 


\subsection{Ethical clearance}

This study required the involvement of numerous stakeholders and institutions working in the region. As the result, the study needs to pass all the necessary steps related to the research ethics. The topic under the investigation is critical and concerns all human kinds. The stake was high. Therefore, ethical clearance was obtained from the Southern Nations and Nationalities and People's Regional Health Bureau institutional ethics review board. Support letters from responsible authorities were obtained and submitted to the organizations/institutions/ individuals participating in the study. Informed written consent was obtained from the study participants before commencing the data collection ( the sample was annexed under the supplementary document \# 3). The purpose of the study was communicated to the study participants. The benefits of the study were equally being shared. The rights of the study participants were maintained across the study period. All the methods were carried out in accordance with the relevant guideline and regulations witnessed by the ethical review board document annexed as a supplementary document \#2. The finding of the study would be communicated to the authorities such as the Regional Health Bureau, Regional President's Office, and other sectors collaborating in the fight against COVID-19 pandemics. The finding also will be published in scientific journals.

[1] 'Woreda' is an administrative hierarchy equivalent to district.

\section{Results}

Since COVID-19 pandemic has multidimensional effect; the response to the problems arising from the disease have necessitated the multisectoral approach. All key informants pointed out their convictions that such a huge problem cannot be countered unless consolidated joint efforts put in place. This is substantiated by the direct statements by the key informants as:

SNNPR government has recognized that proper collaboration is crucial for the prevention and control of the pandemic. Therefore, the process emanated from the very nature of the disease that it intricates almost all spheres of human lives and livelihoods. According to the key informants' expression it is explicates as:

One of the reasons necessitated such joint efforts to intervene the disease prevention and control actions are the very nature of the disease. For one thing, there is no known curative or preventive vaccine so far. Moreover, the disease affects every corner and life endeavors, Therefor, collaborative efforts is a must.

The collaborative efforts of multiple sectors in SNNPR in connection to COVID-19 measures are evidenced first by its organization into main and sub taskforces at the regional, zonal, city administration special woreda and woreda levels. This followed by setting joint plan at regional level that eventually cascaded down to the hierarchies until it reached the kebele [2]level. 
When we see the structure of the main and sub taskforces, there is one main taskforce from the region to the district level and 9-11 sub-taskforces in each stratum. To mention some of these: health, media and communication, trade, resource mobilization, peace and security, sanitation and hygiene, agriculture and food security, public services, education etc...

In the stride to prevent and control the disease, several sectors brought together under the main taskforce as stated above. Some of these sectors have notable experiences of collaborative undertakings on cross cutting issues. Some key informants stated that their earlier experiences have helped for the establishment and strengthening of the current collaborative efforts. The key informants' direct words further echoed this idea as:

As part of the cascaded joint action plan, each sector has prepared its own plan to tackle the multidimensional burden of COVID-19 disease in their respective sector. For instance, the main taskforce allocated a defined responsibility to the health sector (health bureau) on the health services provision related to the disease. The health bureau structured itself into the Emergency Operation Center (EOC) and assigned and Incident Manager (IM). Several taskforces and technical committees have been established under the EOC.

Education sector in its part works in close collaboration with the main task force and act as a sector how to materialize the education process by the time when schools were closed due the fear of the disease. They were given a sectoral mandate to prepare school setups for quarantine, isolation and treatment centers. Another sectoral mandate strictly given for the education sector is how to continue the education process despite the closure of classes.

An issue of food security and ensuring agricultural productivity in the region was strictly given to the agriculture sector. The main taskforce has considered the challenges the disease would impose on this sector. Hence, the sector clearly understood the extent of the damage the disease could cause on the sector and how to tackle such huge burden. The statements from key informants further consolidate this point as:

By the same token, the bureau of Transport and Road Development works in close collaboration with the bureau of Peace and security and bureau of Health to minimize disease transmission via all transport routs in the region. This is further evidenced by the key informants' statements as:

All sectors involved in the taskforce have received sectorial and joint assignments and attempted to effect accordingly. The following key informant information substantiate as:

Under the canopy of the main task force, the media and communication sub-taskforce here at the regional level works in the provision and dissemination of information aiding for the prevention and control of the disease. We do this in collaboration with relevant sectors media institutions and government communication bureau and its respective branches. 
In order to ensure the effectiveness of the multisectoral actions; follow-up, monitoring and evaluation of the actions in the region were done in two ways. One is paying physical visit and the other one is virtual events by the use of technology. As stated by the key informants:

So long as we saw, every taskforce members follow their duties on continues base and monitor and follow it regularly as stated above. The members meet three times a week at the main taskforce and daily on the sub-task force level. By doing so, corrective actions were taken in instant manner.

The monitoring and evaluation process enables whether the intervention is taking towards goal accomplishment or any drawbacks hampering thereof. Both as the main and sub taskforces conducted the supervision and monitoring process. Most of the times the monitoring and follow-up processes were done three times a week at regional, zonal, city administration and woreda levels by the main taskforces.

Several limitations were observed in relation to the intervention of MSA. These are evidenced by the direct words from the key informants as follows:

There is no clear evidence that the approach is leading to the intended goal. Though the public has information on the means of transmission and its eventual effect, it found to be reluctant to implement the principles in the day to day life, according to the informant. Thus, actions and public behaviors are favoring the expansion of the pandemic regardless of support and supervisions.

Key informants mentioned their observation in that the early stage enthusiasm of working together in collaborative and coordinated manner at the main and sub taskforces. However, the practices gradually fade as the time extends. It was manifested that the acting partners, started to stagger their legs in walking together.

The separate sectoral approach eventually started dominating the integrated multsectoral approach, thus, each sector turn back to act separately. This is further evidenced by the statements from the key informants as:

The recent lack of attention among the general public and the leaders in the control and prevention of the disease was seen as the shortcoming. This is evidenced by the key informants' direct words as follows:

Secotal issues took upper hands than the collaborative undertakings. As this is substantiated by the key informants' statement as:

Despite the consolidated joint plan and agreed initiation, there were some lags from members of the taskforces. These were revealed at some district levels. Particularly, some district resource mobilization sub-taskforce did not clearly understand and slowed their efforts to match the demand of the pandemic.

[2] 'kebele' is the lowest administrative hierarchy 
'Zone' is the middle administrative hierarchy between the woreda and the region.

\section{Discussion}

Discussion entails the major findings in line with the aim of the study.

\section{Pattern the MSA integration and coordination in the region, and why it necessitates in such a way to fight the pandemic.}

COVID-19 is a multifaceted problem affecting almost all life dimensions of mankind and any solution to combat its effects must be as wide as its problem spectrum. The study finding indicated that there are increased stakeholders convictions and recognition about the problem and the possible ways to tackle the problem. It was stated that such a huge problem cannot adequately be countered unless consolidated joint efforts put in place. Global experiences clearly indicated that few countries with successful interventions were those who properly utilized multiple sectors. The findings in studies elsewhere support this finding that to revert gross public problems such like COVID-19 need consolidated multisectoral efforts $[29,30,31]$. In similar manner the study in China also recommended better coordination, cooperation and strong solidarity in the joint efforts of fighting against COVID-19 [32].

The Federal Government of Ethiopia's experience remains a wonderful guide for SNNPR to follow this footstep. As clearly indicated in this study, SNNPR government recognized that without proper collaboration, coordination and integration; the prevention and control process would remain futile. Therefore, the process emanated from the very nature of the disease that it convolutes almost all spheres of human lives and livelihoods. Moreover the complexity and strange nature of the disease put global scientific societies in intractable positions and left all global citizens in misery. The study further indicated that the region would be on hotspot unless well-structured resource sharing put forward in an integrated manner. The fast disease transmission across the entire world and in our region, invited all stakeholders to lend hands and work in close collaboration. The finding of this study closely resemble with the study by Martin- Rodriguez, Beaulieu, D’Amour \& Ferrada-Videle, 2005 and Schewartz \& Yen MuhYong, 2017., indicating that any problem such as pandemic diseases need collaborative undertakings (33, 34).

The previous intersectoral collaborative experiences were exhibited in some sectors as has been revealed in this study. It was noted that their earlier intersectoral collaborative experiences have helped for the establishment and strengthening of the current efforts. In connection to this finding Koplan, ButlerJones, Tsang \& Wang; Chen, et al,2020; have mentioned that the collaborative undertakings of experienced stakeholders had been added values in the prevention and control of public health problems such as SARS [35].

It has been seen in this study that the integration and cascading of sectoral undertaking under the umbrella of the core plan. Each sector prepared its own action plan to tackle the multidimensional burden of COVID-19 pandemic in their respective sector and revealed plan interface in their core tasks 
how to prevent and control the spread of the deadly pandemic. The approach abetted sectors to execute their defined responsibilities in a coordinated manner and minimized the overlapping and gapping in the efforts to prevent and control the disease. The finding is supported by the working document of the WHO, FAO and OIE and other related study elsewhere [36, 37].

The commitment and motivation of high level leaders in the intervention of multisectoral approach is irreplaceable. This study has come with the finding that top leader at regional, zonal, city administration and woreda levels have been playing exemplary roles. These were evidenced as they moved into the community to disseminate information about the disease: the burden it could cause, and how to limit its progression and control in as short time as possible. At the inception, the higher official at the region and zones in collaboration with the presidents and vice president of the universities, deans of the colleges of the respective areas in the region; disseminated information at the market places, bus stations, and other

places where mass gathers. Such collaborative undertakings symbolize the multisectoral actions in the prevention and control process of COVID-19 disease. This echoes with the study conducted by Salunke \& Kumar expressed as leadership willingness and policy mandate are the necessary conditions and driving factor for accomplishment of multsectoral actions for a given project or program. [30].

The Multisectoral approach in this study also explicated the active involvements of numerous organizations. Of them some desire special notification are; the youth volunteer group, teachers' association, various organizations of youth and women (youth federation, youth association, league, women association, federation and league) engagements and contribution in the fight against the disease has received the significant attention in this study as for the indications of the collaborative actions. The involvement of the group was multidimensional of which their engagement in information dissemination, resource mobilization, temperature check and related activities that help in the stride against the disease prevention. This study finding is in close resemblance with the directives of the UNICEF and the University of California. Both have stated that adolescents in the fight against COVID-19 should not only be considered as affected population but also as highly effective partners. They are meaningfully engage to be educators and change agents. Their volunteer actions in hand washing campaigns countering discommunication, miscommunication, and stigma in their communities are critical contributions to tackle the problems $[38,39]$.

\section{Monitoring, evaluation follow up and support process in the endeavors of the multisectoral actions:}

It is believed that like any other efforts, activities and duties, the COVID-19 disease prevention and control plan for the joint efforts needs close monitoring and follow up whether all the interventions are leading toward the set goal accomplishment [40]. The study explored whether the interventions of the planned activities to combat the COVID-19 pandemic in the region leads toward the desired goal. As indicated in the study; supportive supervision, follow-up, monitoring and evaluation of the collaborative efforts in the process of COVID-19 prevention and control have exhibited a unique perspective. Unlike the previous approach, this time intensive technology aided monitoring and evaluation has been carried out. Travelling to reach out into the zones and special woredas were strictly minimized due to the disease effect. Instead, 
the virtual meetings through video conferences, zoom meeting, telegram based information exchange became wonderful alternatives bringing stakeholders very close.

The monitoring and evaluation process is being carried out using a check list prepared for this purpose based on the plan developed by the main and sub taskforces earlier. The process enables whether the intervention is taking towards goal accomplishment or any drawbacks hampering thereof. Corrective actions were taken in line with the identified weakness. The whole monitoring and evaluation process were conducted by the joint efforts both as the main and sub taskforces. Equally important in the monitoring and evaluation process was sectoral based supportive supervision, follow-up and evaluation as aligned with the taskforce actions. Most of the times the monitoring and follow-up processes were done three times a week at regional, zonal, city administration and woreda levels by the main taskforces with some degree of staggering. The approach in this study is in line with the $\mathrm{WHO}$ and $\mathrm{FMOH}$ guidelines and working directives $[41,42,43,44]$

\section{Limitation observed in the due course of the multisectoral approaches intervention, monitoring and evaluation?}

Despite encouraging attempts to combat the COVID-19, there are some drawbacks on the intervention of multisectoral collaborative actions [45]. The study has indicated the following limitations of MSA interventions, follow-up and monitoring: failure to meet three times a week as set earlier to discuss on the intervention issues at all level taskforces; shifting attention out of the highly public emergency (the COVID-19) to other local issues; critically low levels of public awareness and participation despite provision of continuous information; failure to stick to measures such as home stay to limit the progression of disease at the early stages due to various reasons; failure to use preventive measures such as face mask while moving outside one's home and in various public gatherings and inability to afford mask regularly can be cited among the many.

The nature of the multisectoral action itself is another challenge in the effect of the process. As rightly indicated in the study, there has been eventual slowdown on the initial enthusiasm of working together in collaborative and coordinated manner at the main and sub taskforces. It was manifested that the acting partners, started to stagger their legs in walking together. This is in line with the study conducted elsewhere indicating that unless proper governance of multisectoral actions put in place, the likely slowdown of the progress of such approach is inevitable [46].

The separate sectoral approach eventually started dominating the integrated multsectoral approach, thus, each sector turn back to act separately. Failure to accomplish the agreed joint plan and submitting exaggerated or absolutely false reports just to please the bosses, lack of personal protective materials and failure to properly and continuously use the personal protective materials are among the limitations mentioned in the study. In addition, the unfavorable attitude and practice of communities at various levels in the process of the disease prevention and control are challenging the joint actions. The observed difference in this regard from person to person and place to place, from urban to rural, some 
misunderstanding such as the disease is only for the urban or developed nation have been the bottleneck in the prevention and control action $[47,48]$.

The recent lack of attention among the general public and the leaders in the control and prevention of the disease was seen as the shortcoming. The surprising issue about this is that failure of most stakeholders to stick to the prevention and control strategies albeit the provision of continuous information about the nature and the impact the disease. Home stay has been one of the strategies to limit disease prevention and control but people avoid this as they choose to die by the disease than by hunger. Thus, they moved out to work and gain some money to fulfill their necessities. This created another worry as they would further fuel the disease propagation. Studies in Ethiopia have substantiated this finding that inadequate acquaintance of the general public and overlapping duties have been some of the drawbacks in the proper interventions of the COVID-19 prevention in the country [29, 49].

The resource mobilization and utilization process is facing another challenge. Lack of common understanding on this issue: failure to execute in accordance to the financial regulation, youth requests of this resource other than the disease prevention and control, and diverting the disease existence as an artifact one as if politically motivated. Some youth lack interest and gut to feel the disease is a real one affecting all dimensions and people are the added challenges.

As has been seen in the study that instead of doing things in the agreed up on joint undertakings, joint intervention, joint monitoring and evaluation few taskforce members interested to reveal their stamina by putting stakes in superior position. This has created some dissatisfaction in collaborating stakeholders and weakened the intersectoral collaborative efforts. The lack of clear accountability and diffusion of responsibility created a spasm in few cases $(50,51)$.

\section{Limitation and strength of the study}

The strength of this study is as it dealt with the very current issue and that is being a concern of all national and global citizens, the timeliness of the study, involvement of as many sectors as possible are some of the strengths. The limitation may be the use of only qualitative method limits its generalizability.

\section{Conclusion And Recommendations}

This study was conducted with the broad aim of exploring the patterns of the multisectoral approach in the fight against COVID-19 pandemic in SNNPR. Based on the study finding, it is concluded that:

The study has clearly indicated that all stakeholders very well recognized the burden of the disease and its propensity to attack all human dimensions: the political, economic, social, demographic and the cultural ones. With the clear understanding of the context, the SNNPR government has established wellstructured organization in the form of main and sub-taskforces across the entire region giving the special attention in which the regional president chairs the main taskforce. The working arrangements and 
organization of various taskforces and committees have created vertical and horizontal connections to support each other, share information, resources and ways of doing things.

Unique multisectoral approach was initiated, intervened to tackle the challenges of the disease. It helped to revitalize the customary beneficial assets of our society such as helping each other at the time of accidents and emergencies.

However, the follow-up, monitoring and evaluation of the MSA, there has been a setbacks irregularity in conducting joint meetings as per the schedule and staggering commitments as time proceeded. Shifting of attention and priority and moving back to the status quo was observed. The glowing nature of enthusiasm eventually started to fade as time lapse. Top leaders occupation by computing priority was observed.

Accordance to the study finding it is recommended that the main and sub taskforces shall reiterate their initial commitments and enthusiasm at all levels; the irregularity in the supportive supervision, follow-up, monitoring and evaluation shall be strengthened; the unique multisectoral efforts exercised in the fighting COVID-19 pandemic has to be shared for other similar activities; and subsequent quantitative study is recommended to come up with the detailed determinants for the success of the multisectoral actions.

\section{Declarations}

\section{Ethical considerations}

Ethical clearance was obtained from the regional health bureau Institutional Review Board in (Additional file 2). Signed consent forms were obtained from the study participants and participants were assured rights to participate or withdraw from the study. The information confidentiality was ensured for the study participants as no identifiers could be stated in the due process of the study and communicating the findings. Anonymity of the direct words of the participants is maintained by using the pseudonyms. The quotes from key informants were presented without indicating the identity of the individual, as they were instead position designated. Study participants were informed about communication of the study finding in various meetings, workshops and publications and verbal consents were obtained.

\section{Consent for the publication}

This manuscript is an extract from the study conducted in the SNNPR, Ethiopia under the title "Exploring Multisectoral Approach to Tackle Public Emergency: The Case of COVID-19 Prevention and Control Preparedness in SNNPR, Ethiopia". All ethical issues including communication of the finding to various stakeholders were properly communicated and their consents were obtained. Study participants signed consent forms and sample signed consent form is attached as annex (Additional file 3).

\section{Availability of Data and Materials}


The data for this study is available in the form of transcripts. The balk of the transcript is in local language and the translated version concisely related to this manuscript is in English. Both transcripts are available.

\section{Funding}

This study is funded by the regional government bureaus (the bureau of finance and health, the policy study and research institute). As we all aware that the COVID-19 pandemic appeared as a global emergency and ruined all dimensions of human livelihood, we did not get full coverage for what the study demanded. Most of the activities were done as a volunteer base but the field work was supported by the bureaus mentioned above. The funding was only covered fieldwork expenses such as travel cost, perdiem, fuel and related incidentals. No fund was allocated for the communication of finding such as publication. There is no interference of the funding entities in all undertakings of the study work except offering the fund for the accomplishment of the study.

\section{Competing interest}

Neither the authors nor the financial supporting bureaus had competing interests in the process of this study undertakings. It was based on identifying evidence to strengthen the pandemic prevention and control processes.

\section{Authors' contribution}

The manuscript is a joint effort of all the authors. AA, the corresponding author was responsible for conceptualizing, conducting data collection, analysis and the write up. AM, FB and SH were responsible for data collection, transcribing and revising transcription, editing and supervising all steps.

\section{Acknowledgement}

This study was incubated while we were discussing the issue of COVID-19 at the Scientific Advisory Team (SAC). Since then, many individuals and institutions have supported the realization of the study. The regional policy study and research institution colleagues deserve special recognition for the kind support and necessary facilitation. To do the field work, the study required budget. The financial support for the data collection and write up sought from the bureau of finance, bureau of health and policy study and research institute. All the heads of these institutions deserve loftier thanks.

We owe sincere gratitude to the key informants of this study at regional, zonal and city administration levels. The study key informants are high ranked government officials with busy schedule. I acknowledge their willingness to share some times for the study despite their extremely busy schedule. They have been instrumental by offering thick information that has shaped the study.

\section{References}


1. Kuruvilla, S. et al. Nusiness not as usual: how multisectoral collaboration can provide transformative change for health and sustainable development. BMJ. 2018; 365. Doi. 10.1136/ bmj.ku771.

2. Multisectoral nutrition strategy 2014-2-25. US Agency for International Development, Washington DC. 2014.

3. Health policy project 2014. "Capacity development resource guide: multisectoral coordination" Washington, DC. Future group.

4. Peake S, Gallagher G, Geneau R, Smith C, Herel M, Fraser H, et al. Health equity through intersectoral action: an analysis of 18 country case studies. Ottawa: Public Health Agency of Canada. And: World Health Organization; 2008.

5. Melis Ap. The evolutionary roots of human collaboration; coordination and sharing of resources. ANN NY Acad Sci. 2013. 1299: 68-76.

6. Tomasello, M. Two key steps in evolution of human cooperation. The interdependence hypothesis. Current anthropology: 2012; 53(6).

7. European Commission. Health inequalities in the EU: Final report of a consortium. Consortium lead: Sir Michael Marmot. Brussels: European Commission, 2013.

8. World Health Organization. Helsinki Statement Framework for Country Action: Health in All Policies. Geneva: 2013a.

9. World health Organization. Health 2020 - A European policy framework and strategy for the 21 st century. Copenhagen: WHO, 2013b.

10. Chen N, Zhou M, Dong X, Qu J, Gong F, Han Y, Qiu Y, Wang J, Liu Y, Wei Y, Xia J, Yu T, Zhang X, Zhang L. Epidemiological and clinical characteristics of 99 cases of 2019 novel coronavirus pneumonia in Wuhan, China: a descriptive study. Lancet 2020; 395: 507-513 [PMID: 32007143 DOI: 10.1016/S0140-6736(20)30211-7]

11. Wang W, Tang J, Wei F. Updated understanding of the outbreak of 2019 novel coronavirus (2019nCoV) in Wuhan, China. J Med Virol 2020 [PMID: 31994742 DOI: 10.1002/jmv.25689].

12. Giovanetti M, Benvenuto D, Angeletti S, Ciccozzi M. The first two cases of 2019-nCoV in Italy: Lafortune G. How much do we know about countries preparedness to respond to pandemics: Insights from two country-level indices. Sustainable Development Solution Network (SDSN): A Golabal Initiative for the United Nations, 2020.

13. World Bank.. Ethiopia in COVID-19 emergency response. Project information document (PID). Report no. PID28927. 2020.

14. National Disaster Risk Management Commission (NDRMC) and OCHA. Ethiopia: COVID-19 humantarian impact situation update no. 01. 31 March 2020.

15. Bureau of Finance (BoF). Annual performance report 2019.

16. CSA, 2007.

17. Regional Health Bureau (BoH) comprehensive action plan for the prevention and control of COVID19, SNNPR. Hawassa, March, 2020. 
18. Camp, W. G. Formulating and Evaluating Theoretical Frameworks for Career and Technical Education Research. Journal of Vocational Educational Research, 2001. 26 (1), 27-39.

19. Himmelman, AT. On the Theory and Practice of Transformational Collaboration; From Social Service to Social Justice. In: Huxham, C., Ed., Creating Collaborative Advantage, Sage Publications, 1996; London, $18 f$.

20. Himmelman, AT. Collaboration for change: definition, decision-making models, roles, and collaboration process guide. Himmelman consulting. 210 Grant street West, Suite 422, Minneapolis: 2002.

21. Harris,J. \& Drimie, S. "Toward an integrated approach for addressing malnutrition in Zambia: a literature review and institutional analysis:," IFPRI discussion papers 1200, International Food Policy Research Institute (IFPRI).

22. Yin, Robert K. Case study research: Design and methods. Los Angeles, CA: Sage.

23. Yin, R.K. Case study research: Design and methods (4th ed.). 2009; Thousand Oaks, CA: SAGE Publications. 2014.

24. Ishak, NM. \& Bekar AY. Developing sampling frame for case study: challenges and conditions. World journal of education. 2014: 4(3).

25. K E. Kassim, A Howze, E. \& MacDonald, G. Interviewing key informants:strategic planning for a global public health management program. The qualitative report: 2013, 18(18) 1-17.

26. Spencer, L., Ritchie, J., O'Connor, W., \& Barnard, M. Analysis: Principles and Processes (chapter 10 pp. 269-293). In C. Ritchie, J. Lewis, C. M. N. Nicholls \& R. Ormston (Eds.). Qualitative Research Practice: A Guide for Social Science Students and Researchers. 2014. London: Sage.

27. Sutton, J. \& Austin, Z. Qualitative research: Data collection, analysis, and management. JCPH. 2015: 68(3).

28. Getaneh Y. et al. Global lessens and potential strategies in combating COVID-19 pandemic in Ethiopia. 2020. Med Rxiv preprint. Doi:10.1101/2020.

29. Salinka, S., \&Lal, D.K. Maintaining accountability for network service. Indian journal of public health. 61: 163-8. 2017.

30. Setyanwan, B.,F \& Lestari, R. A Holistic comprehensive approach: Best practices to improve health policy for COVID-19 pandemic. National public health journal 2020: !5(2).

31. Qian Xu. Et al. Fighting against common enemy of COVID-19: a practice of building a community with a shared future for mankind. Infectious disease of poverty. Commentary. 2020: 9(34).

32. Martin-Rodriguez L.S., Beaulieu, M.D., D’Amour, D. \& Ferrada-Videla, M. The determinats of successful collaboration: A review of theoretical and empirical studies. Journal of inter professional care: 19 sup (1): 132-147.

33. Schewartz, J., \& Yen Muh-Yong. Toward a collaborative model of pandemic preparedness and response: Taiwan's changing approach to pandemics. Journal of microbiology, immunology and infection, 2017: 50 (125-132). 
34. Koplan JP, Butler-Jones D, Tsang T, Wang Y. Public health lessons fromsevere acute respiratory syndrome a decade later. Emerg Infect Dis. 2013;19(6):861-3.

35. Zinsstag J, Schelling E, Waltner-Toews D, Whittaker $M$, Tanner M, editors. One Health: The Theory and Practice of Integrated Health Approaches.Oxford: CAB International; 2015.

36. WHO, OIE (World organization for animal health) \& FAO (2019). Taking a multisectoral one health approach: A tripartite guide to addressing zoonotic diseases in countries.

37. Risk communication and engagement: Practical tips on engaging adolescents and youth in COVID19 response, 2020.

38. Grant, C. \& Osanloo, A. Understanding, Selecting, and Integrating a Theoretical Framework in Dissertation Research: Creating the Blueprint for 'House'. Administrative Issues Journal: Connecting Education, Practice and Research, Pp. 12-22 DOI: 10.5929/2014.4.2.9

39. Multisectoral and intersectoral action for improved health and well-being for all: mapping of the WHO European Region Governance for a sustainable future: improving health and well-being for all. Final report. WHO , Regional Office for Europe, Copenhagen, Denmark. 2018.

40. Kang, E., Park, H.J. \& Kim, J. E.. Health impact assessment as a strategy for intersectoral collaboration. Journal of preventive medicine and public health., 2011: 44(5): 201-209.

41. 2019 Novel Coronavirus (2019-nCov): Strategic preparedness and response plan, 2020.

42. Ouedraogo, O., etal. Policy overview of the multisectoral nutrition planning process: The Progreaa, challeneges and lessons learned from Burkina Faso. Int J Health Plann Mgmt 2019 :35(120-139).

43. Bennett S, Glandon D, Rasanathan K. Governing multisectoral action for health in low-income and middleincome countries: unpacking the problem and rising to the challenge. BMJ Glob Health 2018;3:e000880. doi:10.1136/ bmjgh-2018-000880

44. UN (2020). UN policy brief: The impact of COVID-19 on women.

45. Kitaw, Y. \& Kabba, M. A century after Yehedar beshita (The Spanish flue in Ethiopoia): Are we prepared for the next pandemic? Ethiopian journal of health development, $2018: 32$ (1).

46. Kebede W.S., Geda, N. R., Legesse, B., \& Frkadu, B. Adoptionof preventive practice for COVID-19 in Ethiopia. Frontier Insight. www.frontier.com

47. Allen,P. Accountability for clinical governance: developing collective responsibility for quality in primary care. BMJ 2000:329 (9).

48. Markman, K.D., \& Tetlock, P.E., (2000). I couldn't have known: Accountability, foreseeability and counterfactual denials of responsibility. Britsh journal of social psychology. 39 (313-325).

\section{Figures}




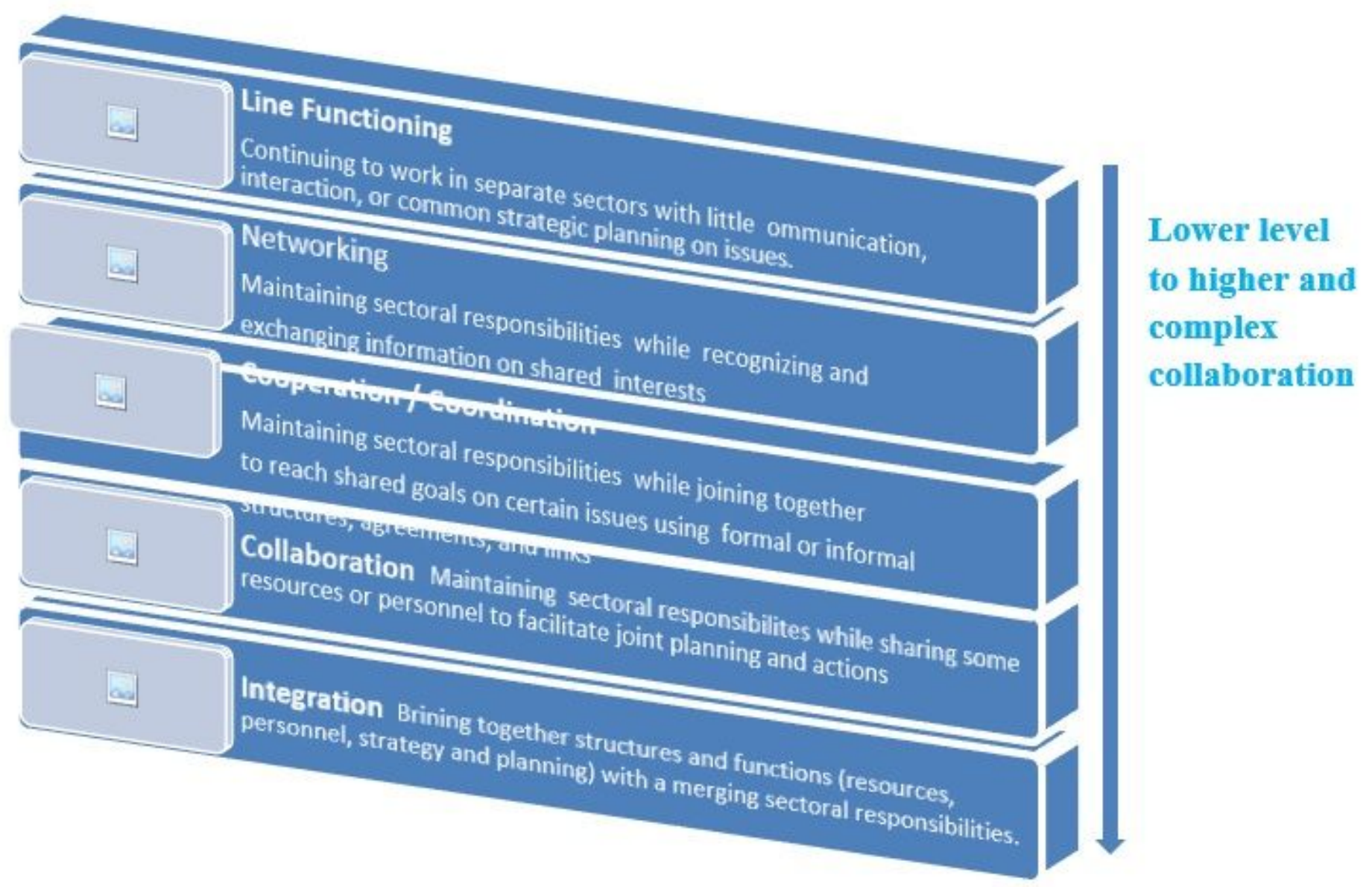

\section{Figure 1}

A continuum of multispectral collaboration. Adopted from Himmelman [20,21]); Harris and Drimie [22]. 


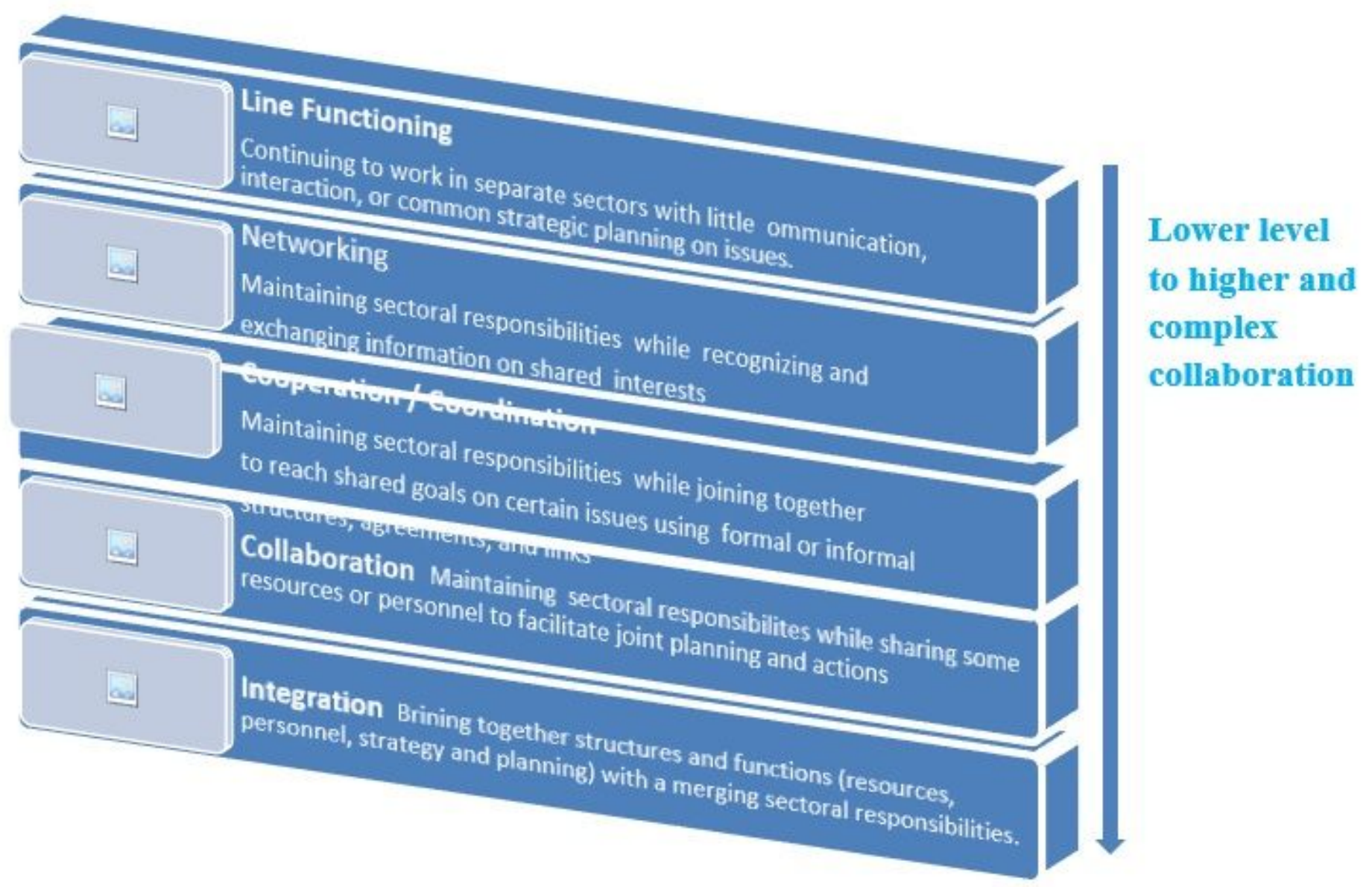

\section{Figure 1}

A continuum of multispectral collaboration. Adopted from Himmelman [20,21]); Harris and Drimie [22].

\section{Supplementary Files}

This is a list of supplementary files associated with this preprint. Click to download.

- AdditionalFile1.pdf

- AdditionalFile1.pdf

- AdditionalFile2.pdf

- AdditionalFile2.pdf

- AdditionalFile3.pdf

- AdditionalFile3.pdf

- AdditionalFile4.pdf

- AdditionalFile4.pdf

- AdditionalFile5.docx

- AdditionalFile5.docx 